Original Article

\title{
Knowledge and Perception of Marital Rape in Pakistan
}

\section{Check for updates}

Copyright $($ C) The Author(s). 2020 This is an open access article distributed under the terms of the Creative Commons Attribution 4.0 International License, which permits unrestricted use, distribution, and reproduction in any medium, provided the original author and source are credited.

\section{(c) (C)}

DOI: 10.29052/2413-4252.v6.i1.2020.54-58

Citation: Sarfraz H, Madani M, Shaikh RA. Knowledge and Perception of Marital Rape in Pakistan. IJWE. 2020; 6(1):54-58

\section{Corresponding Author Email:}

huzaifa.socio@gmail.com

Funding: The author(s) received no specific funding for this work.

Conflicts of Interests: The authors have declared that no competing interests exist.

Received 17/08/2020

Accepted 28/11/2020

Published 14/12/2020

\section{Huzaifa Sarfraz ${ }^{1}$ (D) Munazza Madani ${ }^{1} \&$ Riaz Ahmed Shaikh ${ }^{2}$}

${ }^{1}$ University of Karachi, Karachi-Pakistan

${ }^{2}$ Shaheed Zulfikar Ali Bhutto Institute of Science and Technology, Karachi-Pakistan

\section{Abstract}

Background: In Pakistan, marital rape is not an immediate concern because domestic violence like battering one's wife is considered private. In Pakistan, marital rape is a concept of which the majority are not even aware. Being a society where violence against women is widespread, it is imperative to study the perception and awareness level of Pakistan's marital rape. This study was designed to understand the perception of marital rape among women living in Karachi.

Methodology: The present study is exploratory; based on saturation, the researcher conducted in-depth interviews with eleven participants. The researcher has analyzed the qualitative data by following Creswell Model (2014).

Results: Findings of the study revealed that marital rape is rarely known among women living in Karachi. The institution of the family plays a very weak role in providing sex education to their girls.

Conclusion: This study has concluded that there are no Pakistan sources that can provide awareness regarding women's sexual rights except family.

\section{Keywords}

Marital rape, Pakistan, Sexual Abuse, Violence. 


\section{Introduction}

Marital rape is a word that represents forced sex over one's legal intimate partner. It was when women had not been allowed to give consent or were completely unable to give consent. There are more conditions under which sexual intercourse is considered rape, like, sex when the wife is threatened, sex by taking the wife hostage, when the wife cannot give consent freely; these forms of sexual abuse are termed as marital rape ${ }^{1}$.

Russell wrote a book in 1990 named "Rape in Marriage" has highlighted many issues related to marital rape ${ }^{2}$. According to the literature, this type of rape is far severe than rape by a stranger, as in this rape, a rapist can harm women more easily and multiple times. Marital rape not only harms women physically, but it tears apart a woman's soul, as the harmer is none other than her life partner. The women who had become a victim of marital rape need professional help to overcome the trauma. The long term effects of marital rape can be severe as; in this case, assault is by someone who is supposed to give woman trust, love, comfort and support. These long-term effects include anxiety, shock, depression, insomnia and post-traumatic stress disorder?

Being a society where violence against women is widespread, violence reporting is still hugely stigmatized in Pakistan. Women here do not want to share their abusive marriages as it is considered disrespectful ${ }^{3}$. This is why women here do not want to talk about the problems they face in their sexual lives, which is a negative point to combat violence against women as, according to a report published by a local non-governmental organization (NGO), women in Pakistan face violence irrespective of their social class and religion as the patriarchal culture of the county dictates their lives ${ }^{4}$. In Karachi, a metropolitan city of Pakistan, many women are subjected to physical violence with serious physical and mental health consequences ${ }^{4}$.

Marital rape is a term that is hard to explain and to understand. Being a part of a society where religious and traditional values are always prioritized, it is always difficult to bring up these topics, but covering up or putting these talks under the carpet does not make it a less severe issue. Marital rape is considered a lesser crime as compared to other types of rapes. As a result, this perpetuates rape within marriage by conveying that such acts of violence are less violent than other types. This is also because of the idea that after marriage, the wife becomes property of her husband, so he can treat her in any way he wants. No woman in this world wants to live with a rapist but prioritize being sexually abused rather than being ridiculed by society.

In Pakistan, studies have been conducted on domestic Violence and Violence against women. Still, unfortunately, the researcher was unable to find relevant local literature and data on marital rape. Few types of research were found which have only talked about the issue on a general scale. It was a challenge for the researcher to find the primary data on marital rape in Pakistan ${ }^{5}$.

Although there is no government data to record the exact figure of violence against women in Pakistan $^{6}$, in 2017, a local news agency conducted a survey that found that $93 \%$ of women living in Pakistan experience sexual abuse ${ }^{7}$. Despite all the facts of marital rape, this form of domestic violence has received relatively little attention from society over the years ${ }^{8}$. National surveys on violence against women conducted in Pakistan have emphasized various forms of violence. Still, issues interlinked with women's sexuality, like marital rape, are always being ignored or not addressed ${ }^{9}$. People in Pakistan treat this issue as taboo. Families do not want to talk about the topic to their girls, and victims do not seek professional help and choose to remain silent just to avoid being socially stigmatized $^{10}$.

\section{Methodology}

This study is Exploratory, as it seeks to look for the questions which are not well and deeply studied in Pakistan. The present research's sole purpose is to know the perception of marital rape, a rarely discussed topic in Pakistan. This study is aimed at creating a baseline for future researches in this area. Another reason for selecting exploratory as a 
design of the research is that it will allow the researcher to generate new ideas and assumptions about the topic.

The population of this study is selected as women living in Karachi. The stage of saturation determined the sample size of the study. It is a stage in analyzing the data when the researcher starts getting the same codes because no new information is left in the field. At this stage, the researcher must stop the data collection. In qualitative research, the data's depth is more important than the quantities.

Data was collected through in-depth interviews. These interviews were conducted from person to person. Each interview was held for 1 to 1.5 hours, conducted by the researcher and the participant only. Semi-structured interviews were conducted. In these interviews, a semi-structured questionnaire was used. A semi-structured questionnaire is used in interviews to collect information for both open and close-ended questions and a list of discussion prompts associated with each topic area. Open-ended questions in the questionnaire further helped in probing and collecting the unplanned and unstructured data.

\section{Results \& Discussions}

Very few participants knew about the term 'Marital Rape. 'They were in complete shock when they got to know. Marital rape is discussed in Pakistan neither informal settings like family gatherings because of which married and unmarried. All age groups had the more or less same level of knowledge about the topic as Gentle and James (2019) also found no significant relationship between people concerning unwanted sex and their age and neither informal settings, which include education system as participants with higher qualifications were not found to hold the information regarding marital rape ${ }^{11}$. This pattern was also observed in a study conducted in 2015 that married women who were aware of the physical abuse in marriage did not consider sexual abuse as a form of violence ${ }^{10}$. Studies conducted in the past have also identified younger people as less supportive and more aware of rape myths ${ }^{12}$ and older people as less likely to believe in the existence of marital rape than younger people $e^{13,14}$.

It was a clear hint from the data that the reason for not accepting the idea of rape in marriage goes to society's marital relationship's image and reputation. Many participants clearly stated that it is not possible that this sinful act could be done under the sacred relationship of marriage, as also mentioned by Mohammad $\mathrm{J}^{15}$ that religion Islam views marriage as a sacred union among two people and that to get married is one of the religious obligations. The importance of marriage participants hold has affected the way they make any decision regarding marital rape. Bronnici and Robert (2017) also stated that less reporting of marital rape is why the public is not aware of it and does not consider it any issue ${ }^{16}$. Due to this practice, people did not know about this violent act, and they remain unaware. This is why some participants were completely ignorant and were not ready to accept that rape can be committed in a marriage. For the participants, marital rape was not any serious issue compared to the rape by a stranger. Whatley (2005) declared that marital rape is still considered a less serious issue just because of cultural obligations ${ }^{17}$. The majority of the respondents and participants declared marital rape damaging victims' mental and physical health, but still, they did not want to punish the abusive husbands.

It is reflected by the data that people are not reading by themselves; they are just believing and advocating the unauthentic interpretations by various sources. This behaviour exhibits no appropriate and proper platforms (formal or informal) to provide uniform and authentic religious information over this sensitive issue. This trend was also observed in previous studies, which declared that cultures prefer women's sexuality. Still, discussion over it regarding women's health is underrated and is considered an uncomfortable topic. Due to this, women avoid talking about their sexual issues as they fear judgments from the people ${ }^{18}$. Participants of the study (who knew the term) said that their source of information was 
media. No one knew it from their families. What they have learned about gender roles before and after marriage is by observing and imitating their elders. The majority of them said that topics like this are considered taboo to be discussed in families. A study conducted in Kenya also found findings likewise that girls want their mothers to be open and friendly while communicating culturally sensitive issues, especially those which are related to sexual health but on the contrary, mothers are not that much open as they need to be while communicating such information to their girls ${ }^{19}$.

The majority of participants revealed that their mothers did not ever share anything about marital rape, not even married participants. This means that families do not provide information to their girls regarding marital rape or any of their sexual rights. Only two participants know the victims (one sibling and another neighbour) of marital rape, but they did not know that it is called marital rape. When the researcher discussed marital rape with these two, they realized that their known persons (the victims) are facing marital rape. This finding suggests that married women do not reach out to other married women, and they do not share their intimate matters with others, not even with other married friends or family members. With this result, the researcher developed an impression that there is a lack of communication among people, even among siblings, and this culture gets nourishment by environmental conditioning. Environmental

\section{Conclusion}

The present study concludes that women in Karachi are least aware of the topic of marital rape. There are no proper institutions that can educate women regarding their sexual rights. The family's role has emerged as the strongest for gender socialization, but in Pakistan, families, including mothers, do not provide awareness to their girls regarding marital rape. Cultural obligations bound women for not talking over this issue, due to which the topic of marital rape is not discussed and understood in Pakistan. conditioning plays an important role because it is a common practice that women should not share their problems with others. It could bring ridicule to her and her family. Basile (2002) also declared in his study that women become a victim of unwanted sex with their spouse and keep themselves silent because of a sense of obligation which they have learned from their elders ${ }^{13,14}$. Lack of communication regarding marital rape is the strongest factor that makes people believe that it is not any serious problem brought to the table. People learn values from their environment, which is done via gender roles performed by their mothers and elderly female members of the family and majorly from the religious teachings. Participants declared it a duty of the wife to follow commands of her husband to keep him relaxed and satisfied ${ }^{20}$. Theories suggest that girls learn gender roles from their mothers; they take their mothers as role models. Women are more likely to hold certain positions than men, so girls are more like their mothers than sons like their fathers. Females are reported to be more influence by their mothers, and a mother's guidance affects girls more than a father's encouragement ${ }^{21}$. These teachings also promote the practice of unconditional obedience from wives to their husbands. It had also been observed that people are less likely to support the cause of rape when the abuser in the rape scene is the victim's husband ${ }^{22}$ or consider it less serious than rape done by a stranger ${ }^{23}$.

\section{Acknowledgement}

We would like to thank the participants for sharing their honest thoughts on meeting the study targets.

\section{References}

1. Bergen RK. Issues in intimate violence. Sage; 1998.

2. Russell DE. Rape in marriage, Exp. and rev Edition. United States: Indiana University Press; 1990.

3. Andersson N, Cockcroft A, Ansari U, Omer K, Ansari NM, Khan A, Chaudhry UU. Barriers to disclosing and reporting violence among women in Pakistan: findings from a national household survey and focus group discussions. J. of interpersonal viol. 2010;25(11):1965-85. 
4. Aurat Foundation. Gender-Based Violence in Pakistan: A Scoping Study. Aurat Publication and Information Services Foundation; 2011.

5. Fikree F, Bhatti LI. Domestic violence and health of Pakistani women. Int J Gynecol Obstet 1998; 2:195201.

6. Critelli FM. Women's rights= Human rights: Pakistani women against gender violence. J. Soc. \& Soc. Welfare. 2010;37:135.

7. Kazi M. 93\% of Pakistani women experience sexual violence. Tribune; 2007. [Updated March 8, 2017].Avaialble at: https://ribune.com.pk/story/1348833/93-pakistaniwomen-experience-sexual-violence

8. Troshynski IE, Dirks D. Marital Rape. Encyclopedia of Family Studies. United States: John Wiley \& Sons; 2016.

9. Gah S. Talibanization and Poor Governance: Undermining CEDAW in Pakistan. Second Shadow Report. Lahore, Pakistan: Shirkat Gah. 2007.

10. Madhani Fl, Karmaliani R, Patel C, Bann CM, McClure EM, Pasha O, Goldenberg RL. Women's perceptions and experiences of domestic Violence: An observational study from Hyderabad, Pakistan. J. Interpers. Violence. 2017;32(1):76-100.

11. Gentle S, James E. Knowledge of Unwanted Sex Among Couples in Ikwerre Local Government Area of Rivers State, Nigeria. Inter J In Psyc Social Dev. 2019;7(4):92-101.

12. Blumberg $M L$, Lester $D$. High school and college students' attitudes toward rape. Adolescence. 1991;26(103):727.

13. Basile KC. Attitudes toward wife rape: Effects of social background and victim status. Violence Vict. 2002;17(3):341-354.

14. Basile KC. Prevalence of wife rape and other intimate partner sexual coercion in a nationally representative sample of women. Violence Vict. 2002; 17(5), 511-524.

15. Mohammad JI, Lehmann C. Women's Rights in Islam Regarding Marriage and Divorce. J Law Prac. 2011; 4(3), 1-13.

16. Bonnici R. The outlook of Maltese university students on non-consensual marital sex. Dissertation. Mlata: University of Malta; 2017.

17. Whatley AM. The Effect of Participant Sex, Victim Dress, and Traditional Attitudes on Causal Judgments for Marital Rape Victims. J Family Viol, 2005; 20(3):191-200.

18. Montemurro B, Bartasavich J, Wintermute L. Let's (Not) Talk about Sex: The Gender of Sexual Discourse. Sex Cult. 2015; 19, 139-156.

19. Crichton J, Ibisomi L, Gyimah SO. Mother-daughter communication about sexual maturation, abstinence and unintended pregnancy: Experiences from an informal settlement in Nairobi, Kenya. J Adolescence. 2012;35(1):21-30.

20. Sarfraz H. Marital Rape; A Myth or Fact?. IJWE. 2017;3(1):19-21.

21. Brogan D, Kutner NG. Measuring sex-role orientation: A normative approach. J Marr. Family. 1976;38(1):3140.

22. Kirkwood MK, Cecil DK. Marital rape: A student assessment of rape laws and Local Government Area of Rivers State, Nigeria. Inter J Inno Psyc Social Dev. 2001; 7(4): 92-101.

23. Monson CM, Langhinrichsen-Rohling J, Binderup T. Does "no" really mean "no" after you say "yes"? Attributions about date and marital rape. J Interper Viol. 2000; 15:1156-1174. 